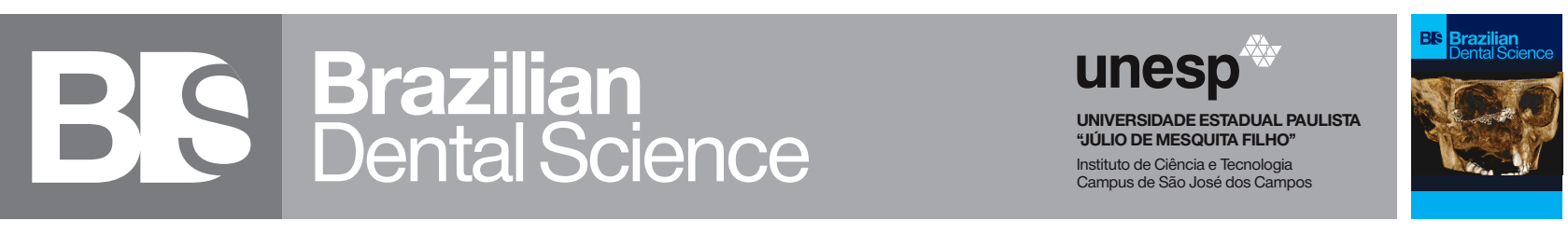

\title{
Maxillary osteosarcoma: a case report and review of maxillary sinus space-occupying lesions
}

Osteossarcoma maxilar: um relato de caso e análise de lesões que ocupam o espaço do seio maxilar

Abbas SHOKRI ${ }^{1}$, Kousar RAMEZANI ${ }^{2}$

1 - Dental Implant Research Center - Department of Oral and Maxillofacial Radiology - Dental School - Hamadan University of Medical Sciences - Hamadan - Iran.

2 - Oral and Maxillofacial Radiology Department - Dental School - Hamadan University of Medical Sciences - Hamadan - Iran.

\begin{abstract}
Osteosarcoma is a relatively rare lesion in the maxillary bone. The proximity of the lesion to the maxillary sinus provides a null space with the minimum resistance to progress prior to manifest clinically, which makes the early diagnosis more critical. We report a case of maxillary osteosarcoma in a 21-year old male patient who was presented with the chief complaint of the pain and swelling on the left side of palate since 2 months earlier. A conebeam computed tomography of the maxilla revealed a diffuse hyper-intense entity at the left side of the maxilla. Totally-occupied maxillary sinus space, asymmetric periodontal ligament widening of the involved teeth and spiculated and sunray periosteal reaction were recognized. The diagnosis of osteosarcoma was established and confirmed by histopathology. This article reviews the sinus-occupying lesion in the following and describes the lesions originate within the maxillary sinus or arise from the adjacent odontogenic components.
\end{abstract}

\section{KEYWORDS}

Case report; Maxillary sinus; Osteosarcoma.

\section{RESUIMO}

O osteossarcoma é uma lesão relativamente rara no osso maxilar. A proximidade da lesão ao seio maxilar proporciona um espaço vazio com resistência mínima ao progresso da lesão antes de se manifestar clinicamente, o que torna o diagnóstico precoce mais crítico. Relatamos um caso de osteossarcoma maxilar em um paciente do sexo masculino de 21 anos que se apresentou com queixa principal de dor e inchaço do lado esquerdo do palato desde 2 meses antes. Uma tomografia computadorizada Cone Beam da maxila revelou uma entidade hiperintensa difusa do lado esquerdo da maxila. Seio maxilar totalmente ocupado, alargamento assimétrico do ligamento periodontal dos dentes envolvidos e reação periosteal espiculada e em raios de sol foi reconhecida. O diagnóstico de osteossarcoma foi estabelecido e confirmado por histopatologia. Este artigo analisa a lesão que ocupa o seio maxilar e descreve as lesões originadas dentro do seio maxilar ou que surgem de componentes odontogênicos adjacentes.

\section{PALAVRAS-CHAVE}

Relato de caso; Seio maxilar; Osteossarcoma. 


\section{INTRODUCTION}

$\mathrm{O}$ steosarcoma (OS) is known as the most common primary malignancy of the bones [1]. It occurs most commonly in the long bone metaphyseal plates of adolescents and young adults $[2,3]$. OS of head and neck is usually seen in the third or fourth decade with an average age of 45 , which could be induced by prior radiotherapy or chemotherapy $[4,5]$. Life expectancy is longer and the prognosis is better in patients with head and neck OS than those with OS of extremities $[6,7]$. The onset of head and neck OS is 10 to 20 years later and distant metastasis is less frequent than long bone OS [8]. Moreover, local recurrence is more probable in head and neck OS due to difficult accessibility and complicated anatomy of the region [9].

OS of the jaws represents 2 to $10 \%$ of all OSs, nearly $10 \%$ of which is the result of radiation [10]. The mandible is involved more commonly than maxilla [11]. Its incidence is equal in both genders. Ogunlewe et al. reported data of patients with OS of the jaws in a 21-year period and suggested that there is a predominant incidence of mandible OS in the females, while OS of the maxilla presents a tendency to the males [12]. The most common symptoms are swelling, pain, ulceration, paresthesia and numbness of the lips $[10,13]$.

Head and neck OS presents a diagnostic challenge on account of rarity, nonspecific complications, unusual presentations and absence of typical radiologic features in some patients [10, 14].

OShasill-defined borders on theradiography. Its internal structure could be radiolucent, mixed or radiopaque. Invasion to the periosteum or expansion of the lesion might lead to the periosteal reaction that could appear as typical sunray, Codman's triangle and less probably laminar. The involved teeth have asymmetric PDL-widening, similar to the other malignancies that involve teeth. OS can violate the cortical bones and invade to the adjacent soft tissues. OSs with radiolucent internal structure appear similar to fibrosarcoma and metastatic carcinomas. But if osseous structures could be recognized within the lesion it could be misinterpret as chondrosarcoma. Spiculated periosteal reaction appears in metastasis from prostate and breast. Hemangioma can mimic such an appearance. Internal structure of fibro-osseous lesion, bone dysplasias and ossifying fibroma could simulate OS on radiography and histopathology but they are less invasive more demarcated and in these cases the definitive diagnosis is established based on the radiographic features, which makes the role of radiography more important in the diagnosis and further treatment [15].

\section{CASE REPORT}

A 21-year old male patient presented to oral and maxillofacial radiology center with the chief complaint of pain and swelling in the left side of palate since 2 months earlier. He did not have other considerable medical histories. He did not report a history of radiotherapy or chemotherapy.

On extra- and intraoral examination a mild bony hard swelling on the palatal side of the left maxillary alveolar process, extending from the distal aspect of lateral incisor to the tuberosity was noticed. The overlying mucosa was intact. All the teeth of the upper left quadrant were normal on the vitality test. There was not any sign of nasal obstruction or ophthalmic involvement. No cervical lymphadenopathy was discovered.

A cone-beam computed tomography (CBCT) of the maxilla and maxillary sinuses (Figure 1) revealed a diffuse homogenous hyper-intense lesion at the left side of the maxilla with poorlydefined margins, spanning from the distal aspect of maxillary left canine to the tuberosity and from the alveolar crest of maxilla to the orbital floor. Asymmetric PDL-widening in teeth 12, 13, 14, 15 and 16 was obvious in all sagittal, coronal and axial cuts. There was no root resorption in the involved teeth. The lesion destructed the medial wall and floor of the left maxillary antrum, encroaching to the antral space, as which the whole maxillary sinus space was occupied by the invaded lesion. The floor and lateral wall of the left nasal fossa were destructed. Inferior and medial turbinates were invaded by the lesion and inferior meatus was obstructed as the result of the inferior turbinate collapse. The palatal plate of left maxillary alveolar process could not be distinguished due to extensive destruction and massive spiculated and sunray periosteal reaction. The Buccal cortical plate was almost intact, even though local erosions were noticed in specific areas. Internal and external pterygoid plates were intact. The diagnosis of osteosarcoma was established and confirmed by histopathology. The patient underwent surgical resection and chemotherapy. 


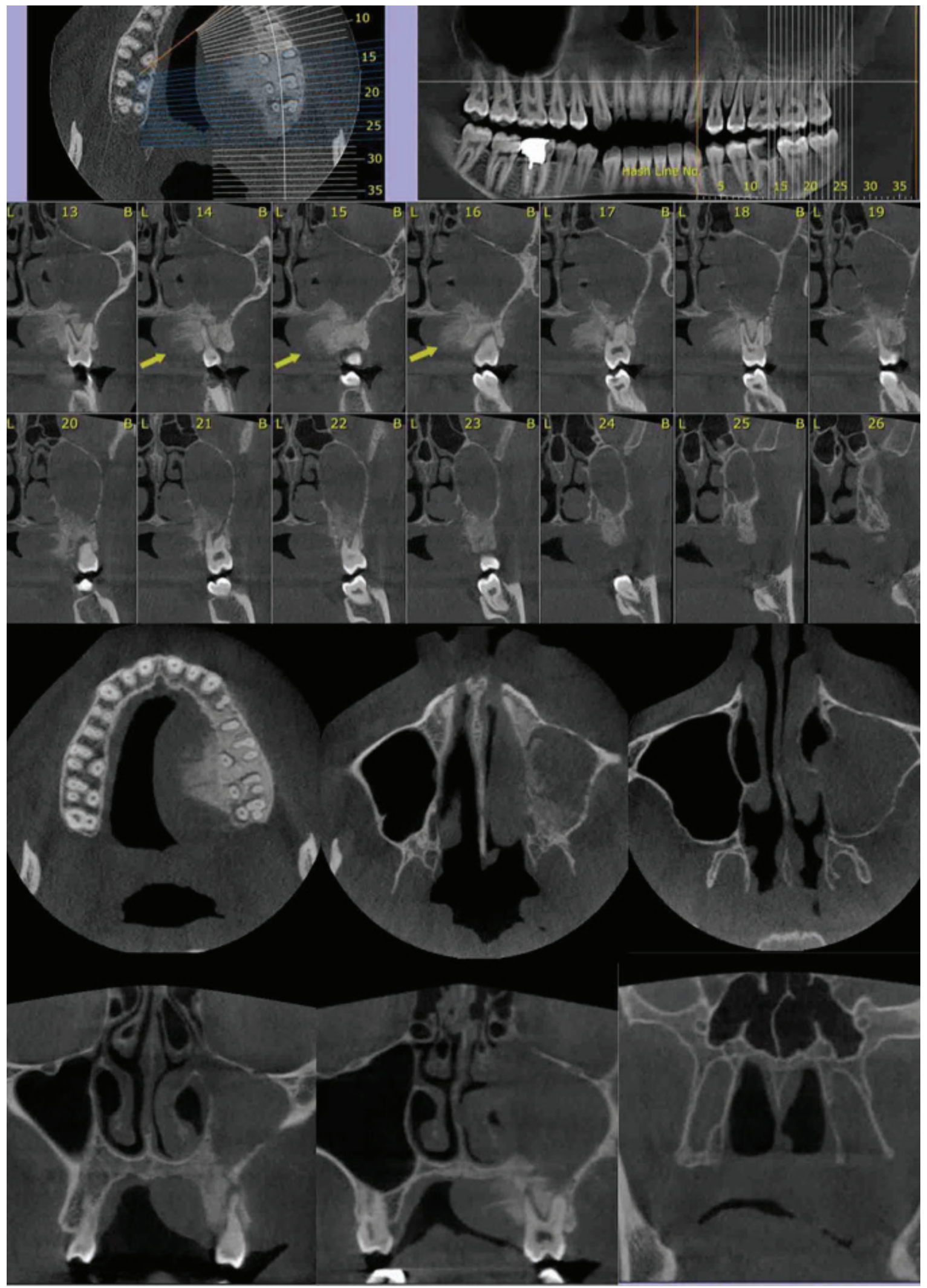

Figure 1 - Cone-beam computed tomography of the lesion. 


\section{DISCUSSION}

Craniofacial region is not a common site for OS development. OS of the jaws represents approximately $1 \%$ of head and neck malignancies and has lower grades and less distant metastases compared to the OS of the long bones but they have higher mortality with local disease which makes the importance of early diagnosis and treatment more crucial [13]. Prior radiotherapy is an important inducing factor for OS of the head and neck [14]. OS can develop from a primary bone disease like fibrous dysplasia or osteoblastoma [16]. The most common symptom of OS of the jaws is painless swelling, followed by teeth displacement and parasthesia. In case of sinonasal cavity involvement epistasis and nasal obstruction would be reported by patients [7].

Radiographic and histologic diagnosis of OS of the jaws is challenging $[17,18]$. Three factors determine the radiographic features of OSs: bone formation, bone destruction and periosteal reaction, which appear as radiolucent, radiolucent-radio opaque or radio opaque in radiographic evaluations depending on the degree of mineralized tissue formation. The most common radiographic feature is mixed appearance with irregular margins [19]. Perforation of the cortical plates and invasion to the surrounding soft tissues is common. When periosteal reaction manifest as bone formation perpendicular to the cortical plates, the typical sunray (sunburst) or hair-on-end appearance would be featured. Laminated, Codman triangle and disorganized periosteal reaction have been reported in OS [20]. Asymmetric PDL-widening is another radiographic finding. None of the mentioned radiographic findings are not pathognomonic for the OS and could be found in other entities including chondrosarcoma, metastases and lymphoma [14]. In our case the left maxillary sinus cavity was invaded and filled with the lesion. Determining the origin of maxillary sinus lesions has always been a challenge. Maxillary sinus contains different types of cells and has located adjacent to the odontogenic components of the maxilla. As a result, it could be involved by various entities. Airfilled space of sinus would have a contrast with even low-intensity lesions, making the role of radiography more valuable in diagnosis before invasive lesions and malignancies take advantage of its empty space to progress. Radiologic features of maxillary sinus lesions help to determine their origin and behavior to get close to a more definitive diagnosis. Categorizing the wide spectrum of lesions involving the maxillary sinuses and defining the expected radiographic effects on the maxillary sinuses and surrounding structures makes it more straightforward to get a deterministic diagnosis. (Table I) presents the common situations that involve the maxillary sinuses.

The most predominant histologic variants of OS are osteoblastic, fibroblastic and chondroblastic variants. Chondroblastic OS is the most common variant presents in the jaws, as which may hesitate the pathologist to get a deterministic diagnosis between OS and chondrosarcoma [7]. The tumor size, location and grade determine the prognosis of the lesion, even though there is controversy about the role of tumor size [21, 22]. Early diagnosis and surgical intervention increase the survival chance. Surgical resection with adequate safe margin and adjunct chemotherapy is the protocol of the treatment followed by most centers. 
Table I - Common situations involve the maxillary sinuses.

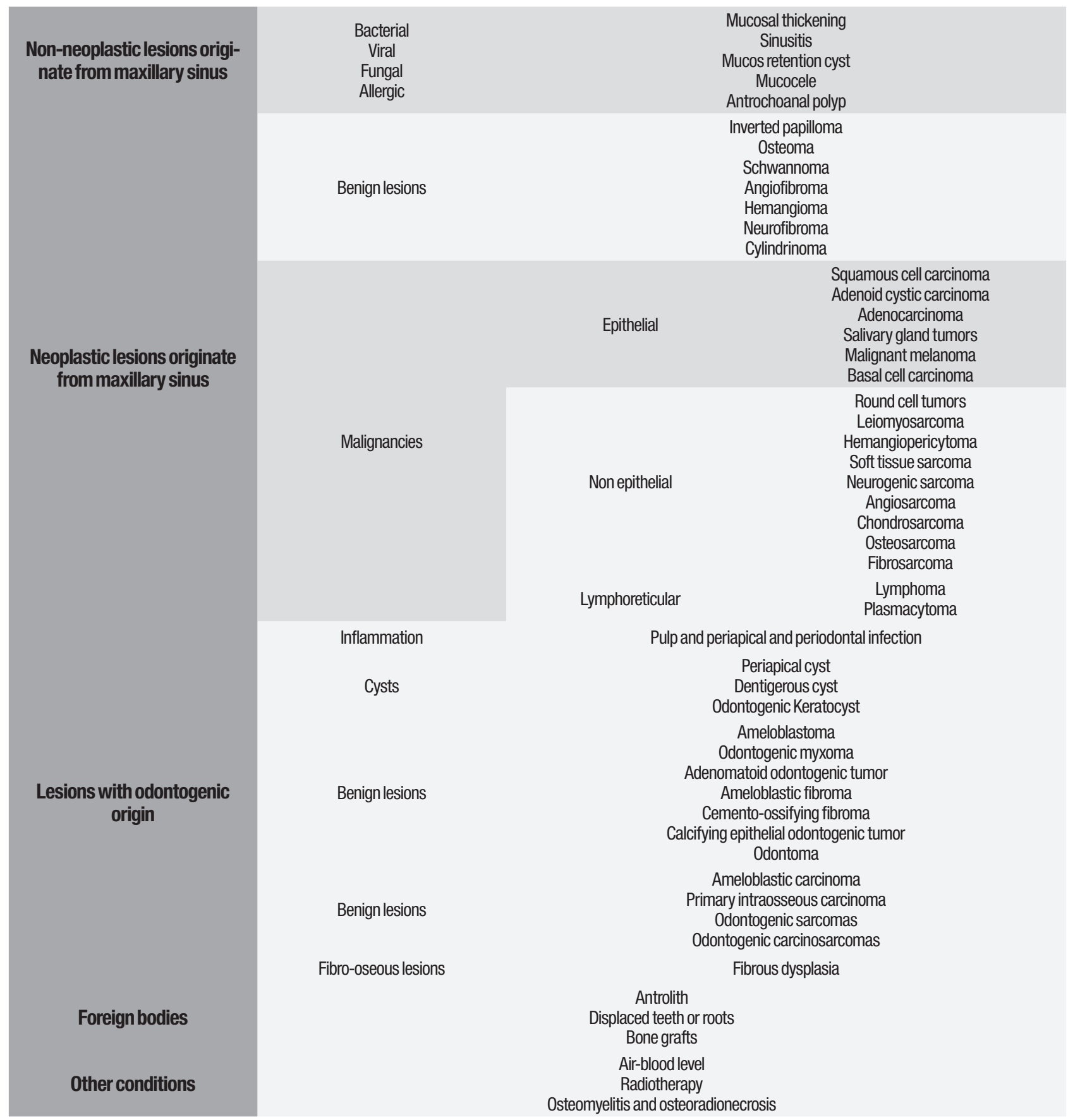

\section{CONCLUSION}

OS of the jaws is a rare entity that yet there are difficulties related to its diagnosis. Being familiar with imaging features of OS helps to get the diagnosis with higher confidence. An aggressive mixed radiolucent-radio opaque lesion with irregular borders that widens PDL spaces of involved teeth asymmetrically and simulate periosteal reaction could be suggestive of OS. 


\section{REFERENCES}

1. Huang X, Zhao J, Bai J, Shen H, Zhang B, Deng L, et al. Risk and clinicopathological features of osteosarcoma metastasis to the lung: $A$ population-based study. Journal of bone oncology 2019;16:100230.

2. Heng M, Gupta A, Chung PW, Healey JH, Vaynrub M, Rose PS, et al. The role of chemotherapy and radiotherapy in localized extraskeletal osteosarcoma European journal of cancer (Oxford, England: 1990) 2019.

3. Luo Z, Chen W, Shen X, Qin G, Yuan J, Hu B, etal. Head and neck osteosarcoma: CT and MR imaging features. Dento maxillo facial radiology 2019:20190202.

4. Mendenhall WM, Fernandes R, Werning JW, Vaysberg M, Malyapa RS, Mendenhall NP. Head and neck osteosarcoma. American journal of otolaryngology 2011;32:597-600.

5. Liang L, Zhang T, You Y, He Q, Fan Y, Liao G. An individual patient data metaanalysis on the effect of chemotherapy on survival in patients with craniofacial osteosarcoma. Head \& neck 2019;41:2016-23.

6. Chen Y,Gokavarapu S, Shen Q, Liu F, Cao W, Ling Y, et al. Chemotherapy in head and neck osteosarcoma: Adjuvant chemotherapy improves overall survival. Oral oncology 2017;73:124-31.

7. Kumaravelu C, Sathya Kumar D, Chakravarthy C, Kishore Kumar RV, Rajasekhar G, Gokul Chandra Reddy M, etal. Chondroblastic osteosarcoma of maxilla: a case report and review of literature. Journal of maxillofacial and oral surgery 2009;8:290-3.

8. Seng D, Wu J, Fang Q, Liu F.Prognosis of osteosarcomas in the mandible: 15-year experience of 55 patients. Medicine 2019;98:e13875.

9. Chen Y,Shen Q, Gokavarapu S, Lin C, Yahiya, Cao W, etal. Osteosarcoma of head and neck: A retrospective study on prognostic factors from a single institute database. Oral oncology 2016;58:1-7.

10. Nthumba PM. Osteosarcoma of the jaws: a review of literature and a case report on synchronous multicentric osteosarcomas. World journal of surgical oncology 2012;10:240.

11. Durnali A, Alkis N, Cangur S, Yukruk FA, Inal A, Tokluoglu S, etal. Prognostic factors for teenage and adult patients with high-grade osteosarcoma: an analysis of 240 patients. Medical oncology (Northwood, London, England) 2013;30:624.
12 Ogunlewe MO, Aiayi OF, Adeyemo WL, Ladeinde AL, James 0 . Osteogenic sarcoma of the jaw bones: a single institution experience over a 21-year period. Oral surgery, oral medicine, oral pathology, oral radiology, and endodontics 2006;101:76-81

13. Kuo C, Kent PM. Young Adult With Osteosarcoma of the Mandible and the Challenge in Management: Review of the Pediatric and Adult Literatures. Journal of pediatric hematology/oncology 2019;41:21-7.

14. LuoZ, Chen W, Shen X, Qin G, Yuan J, Hu B, etal.CT and MRI features of calvarium and skull base osteosarcoma (CSBO). The British journal of radiology 2020;93:20190653.

15. White SC, Pharoah MJ. White and Pharoah's Oral Radiology E-Book:Principles and Interpretation: Elsevier Health Sciences; 2018.

16. Pack SE, AI Share AA, Quereshy FA, Baur DA. Osteosarcoma of the mandible arising in fibrous Dysplasia-A case report. Journal of Oral and Maxillofacial Surgery 2016;74:2229. et- e4.

17. Desai D, Pandith S, Jeergal PA. Fibroblastic variant of osteosarcoma:a challenge in diagnosis \& management. The open dentistry journal 2010;4:211.

18. Padilla RJ, Murrah VA. The spectrum of gnathic osteosarcoma: caveats for the clinician and the pathologist. Head and neck pathology 2011;5:92-9.

19. Doval D, Kumar R, Kannan V, Sabitha K, Misra S, Kumar MV, etal. Osteosarcoma of the jaw bones. British Journal of Oral and Maxillofacial Surgery 1997;35:35762.

20. Rana RS, Wu JS, Eisenberg RL. Periosteal reaction. American Journal of Roentgenology 2009;193:W259-W72.

21. Granados-Garcia M, Luna-OrtizK, Castillo-Oliva HA, Villavicencio-Valencia V, Herrera-Gómez A, Mosqueda-Taylor A, etal. Free osseous and soft tissue surgical margins as prognostic factors in mandibular osteosarcoma. Oral oncology 2006;42:172-6.

22. Altuwairgi 0,Papageorge MB,Karp DD. Maxillary chondroblastic sarcoma: presentation of two cases and a literature review. Journal of oral and maxillofacial surgery 1996;54:1357-64.

\section{Dr Kousar Ramezani}

(Corresponding address)

Department of Oral \& Maxillofacial Radiology, Dental School, Hamadan University of

Medical Sciences, Hamadan, Iran.

Shahid Fahmideh Blvd

Opposite of Mardom park

Hamadan, Iran

Date submitted: 2020 Mar 06

E-mail: kosar.ramezani@gmail.com

Accept submission: 2020 May 12 